\title{
The Small GTPase Rac1 Regulates Auditory Hair Cell Morphogenesis
}

\author{
Cynthia M. Grimsley-Myers, ${ }^{1}$ Conor W. Sipe, ${ }^{1}$ Gwenaëlle S. G. Géléoc, ${ }^{2,3}$ and Xiaowei Lu ${ }^{1}$ \\ Departments of ${ }^{1}$ Cell Biology, ${ }^{2}$ Neuroscience, and ${ }^{3}$ Otolaryngology, University of Virginia, Charlottesville, Virginia 22908
}

Morphogenesis of sensory hair cells, in particular their mechanotransduction organelle, the stereociliary bundle, requires highly organized remodeling of the actin cytoskeleton. The roles of Rho family small GTPases during this process remain unknown. Here we show that deletion of Racl in the otic epithelium resulted in severe defects in cochlear epithelial morphogenesis. The mutant cochlea was severely shortened with a reduced number of auditory hair cells and cellular organization of the auditory sensory epithelium was abnormal. Rac1 mutant hair cells also displayed defects in planar cell polarity and morphogenesis of the stereociliary bundle, including bundle fragmentation or deformation, and mispositioning or absence of the kinocilium. We further demonstrate that a Rac-PAK (p21-activated kinase) signaling pathway mediates kinocilium-stereocilia interactions and is required for cohesion of the stereociliary bundle. Together, these results reveal a critical function of Racl in morphogenesis of the auditory sensory epithelium and stereociliary bundle.

\section{Introduction}

In the mammalian inner ear, mechanosensory hair cells located within a specialized sensory epithelium in the cochlea, the organ of Corti (OC), are responsible for sound detection. These hair cells are interdigitated with nonsensory support cells, and each contain on their apical surface a V-shaped stereociliary bundle (or hair bundle) with intrinsic structural polarity: the actin-based stereocilia are organized into rows of graded heights, forming a staircase-like pattern. Furthermore, auditory hair bundles are uniformly oriented across the $\mathrm{OC}$, with the $\mathrm{V}$ pointing toward the outer (lateral) border of the cochlear duct. These features are essential for the correct perception of sound and are established by an intricate gene network during development (Frolenkov et al., 2004; Petit and Richardson, 2009).

In the mouse, hair bundle development and maturation proceed in two perpendicular gradients, from the base to the apex and from the medial to lateral side of the cochlea over a period from late embryogenesis to the first two postnatal weeks (Frolenkov et al., 2004; Petit and Richardson, 2009). During the initial phase, a single tubulin-based kinocilium, derived from the primary cilium, migrates from the center to the lateral edge of the hair cell apex. Concomitant with this migration, microvilli around the kinocilium elongate to form stereocilia of graded heights. By the

\footnotetext{
Received Aug. 14, 2009; revised 0ct. 23, 2009; accepted Nov. 5, 2009.

This study was supported by National Institutes of Health (NIH) Grants R01 DC009238 (to X.L.) and DC008853 (to G.S.G.G.). C.G.-M. is supported by a fellowship from the Hartwell Foundation. C.S. is supported by NIH Training Grant $5 T 32$ GM008136-24 to the University of Virginia. We thank Paul Adler, Jeff Holt, Bettina Winkler, and Jason Kinchen for helpful comments on the manuscript, Jan Reddick for assistance with electron microscopy, Lixia Liu for technical support, Thomas Parsons for plasmids, and James Bartles, Thomas Friedman, Jeremy Nathans, Yanshu Wang, and Bette Dzamba for antibodies.

The authors declare no conflicts of interest.

Correspondence should be addressed to Xiaowei Lu, Department of Cell Biology, University of Virginia, Box 800732, 1300 Jefferson Park Avenue, Charlottesville, VA 22908. E-mail: xl6f@virginia.edu.

DOI:10.1523/JNEUROSCI.3998-09.2009

Copyright $\odot 2009$ Society for Neuroscience ～0270-6474/09/2915859-11\$15.00/0
}

end of embryogenesis, nascent hair bundles exhibit a crescent shape with the kinocilium centered next to the tallest stereocilia. Next, during the first postnatal week, stereocilia undergo further row-specific, differential outgrowth, eventually forming a hair bundle with a staircase organization. Finally, the kinocilium retracts around postnatal day 10 .

Tremendous progress has been made toward understanding the molecular mechanisms that regulate hair bundle morphogenesis. In particular, genetic analysis and cloning of deafness mutations in humans and mice have identified a number of structural and regulatory proteins of the actin cytoskeleton (El-Amraoui and Petit, 2005; Leibovici et al., 2008; Petit and Richardson, 2009). In addition, a Wnt/planar cell polarity (PCP) pathway, with both evolutionarily conserved (such as the Frizzled and Dishevelled proteins) and novel (such as Scrb1 and PTK7) components, plays an important role in regulating cochlear elongation and hair bundle orientation (Rida and Chen, 2009).

Despite the importance of the actin cytoskeleton in hair cell morphogenesis, the roles of Rho GTPases, central regulators of actin dynamics, in this process remain poorly understood. Rho family members, including Rho, Rac, and Cdc42, have been shown to influence cell migration, cell-cell adhesion, microtubule dynamics, cell proliferation, apoptosis, and gene transcription (Jaffe and Hall, 2005). Thus, Rho GTPases could potentially regulate many aspects of cochlear epithelial morphogenesis.

In this study, we show that the small GTPase Racl plays a critical role in the morphogenesis of the $\mathrm{OC}$ and the auditory hair bundles. Furthermore, we provide evidence that Racl regulates interactions between the kinocilium and stereocilia via p21activated kinase (PAK), which is required for the cohesion of the developing hair bundle. These results establish Racl as a key regulator of auditory hair cell morphogenesis. 


\section{Materials and Methods}

Mice. The Rac1 conditional allele, Foxg1-Cre mice, and Pax2-Cre mice were previously described (Hébert and McConnell, 2000; Glogauer et al., 2003; Ohyama and Groves, 2004). All strains were maintained on a mixed genetic background. $\operatorname{Ltap}^{L p}$ mice were obtained from the Jackson Laboratory and CD1 mice from Charles River. Foxg1-Cre; Rac1 ${ }^{\mathrm{KO} /+}$ males were bred with $\mathrm{Racl}^{\mathrm{CO} / \mathrm{CO}}$ females to generate Foxg1-Cre; $\mathrm{Racl}^{\mathrm{KO} / \mathrm{CO}}$ mutants and littermate controls. $\mathrm{Pax} 2-\mathrm{Cre} ; \mathrm{Racl}^{\mathrm{CO} /+}$ females were bred with $\mathrm{Rac1}{ }^{\mathrm{CO} / \mathrm{CO}}$ males to generate Pax2-Cre; $\mathrm{Rac1}{ }^{\mathrm{CO} / \mathrm{CO}} \mathrm{mu}$ tants and littermate controls. PCR genotyping of the Racl alleles was performed as described previously (Glogauer et al., 2003). Mice were genotyped for Cre using the following primers: 5 '-AGAACCTGAAGATGTTCGCG-3' and 5'-GGCTATACGTAACAGGGTGT-3'. For timed pregnancies, the morning of the plug was designated as embryonic day 0.5 (E0.5), and the day of birth postnatal day 0 (P0). Animal care and use was in accordance with National Institutes of Health guidelines and was approved by the Animal Care and Use Committee at the University of Virginia.

Immunohistochemistry. Temporal bones were dissected and fixed in $4 \%$ paraformaldehyde for $1 \mathrm{~h}$ at room temperature or overnight at $4^{\circ} \mathrm{C}$ and washed in PBS. For whole mounts, cochleae were dissected out of the temporal bones in PBS and the anlage of Reissner's membrane removed to expose the sensory epithelium. For sectioning, fixed temporal bones were dissected in PBS, equilibrated overnight in 30\% sucrose and then embedded and snap frozen in OCT (Tissue Tek). Temporal bones were cryosectioned at $14 \mu \mathrm{m}$ thickness. Sections or dissected cochleae were incubated in PBS $+5 \%$ heat-inactivated goat serum $+0.1 \%$ Triton + $0.02 \% \mathrm{NaN}_{3}$ (blocking solution) for $1 \mathrm{~h}$ at room temperature, followed by overnight incubation with primary antibodies diluted in blocking solution at $4^{\circ} \mathrm{C}$. After three washes in PBS $+0.1 \%$ Triton, samples were incubated with secondary antibodies diluted in blocking buffer for $1 \mathrm{~h}$ at room temperature. Cochleae were flat-mounted in Mowiol with $5 \% \mathrm{~N}$-propyl gallate. Images were collected using a Zeiss LSM 510 Meta confocal microscope and LSM Image Browser software, or using a DeltaVision deconvolution microscope and SoftWoRx software (Applied Precision). Images were then processed in Adobe Photoshop (Adobe Systems). For flat-mount images of the OC, $Z$-stacks of $5 \mu \mathrm{m}$ or more were taken at $0.2 \mu \mathrm{m}$ intervals, encompassing a volume from the tips of the hair bundle to the apical cytoplasm of the hair cell. When comparing protein localizations, the same exposure conditions were used for controls and mutants, and every plane of the $Z$-stack was carefully examined to ensure comparisons were made at equivalent axial levels. All comparisons were performed at equivalent locations along the length of the cochlear duct. The following primary antibodies were used: anti-Racl (1:1000, BD Biosciences), anti-myosin VI (1:1000, Proteus BioSciences), anti-myosin VIIa (1:1000, Proteus BioSciences), anti-acetylated tubulin (1:500, Sigma), anti- $\alpha$-tubulin (1:1000, Sigma), anti- $\beta 1 / \beta 2$-tubulin (1:200, Sigma), anti- $\alpha$-spectrin (1:100, Millipore), anti-E-cadherin (1:1000, Sigma), anti- $\beta$-catenin (1:1000, Cell Signaling Technology), anti-Fz3 [1:200 (Wang et al., 2006b)], Pan-Espin antibody [1:500 (Sekerková et al., 2006)], anti-myosin XVa [1:150 (Belyantseva et al., 2005)], anti-Whirlin antibodies [1:300 (Belyantseva et al., 2005)], anti-harmonin (1:100, ProteinTech Group), anti-phosphoPAK1/2/3 (1:200, Biosource), and anti-p27 ${ }^{\text {kipl }}$ (1:200, Neomarkers, used after antigen retrieval by boiling in $10 \mathrm{~mm}$ citrate buffer, $\mathrm{pH} 6.0$, for $10 \mathrm{~min}$ ). Alexa-conjugated secondary antibodies (1:1000), Alexaand rhodamine-conjugated phalloidin (1:100), and Hoechst 33342 (1: 10,000) were from Invitrogen.

Cell culture transfection and cDNA constructs. 293T cells were transfected in six-well plates using the FuGene reagent (Roche) according to the manufacturer's instructions. Protein lysates were isolated $24 \mathrm{~h}$ after transfection and analyzed by Western blotting. Samples were run in duplicates on the same gel and immunoblotted separately with anti-Racl or anti-HA antibodies. pcDNA3.1-Rac1-3xHA, pcDNA3.1-Rac2-3xHA, and pcDNA3.1-Rac3-3xHA plasmids were provided by Dr. Thomas Parsons (University of Virginia, Charlottesville, VA).

Quantitation of hair cell number, organ of Corti length, and hair bundle phenotype in Foxg1-Cre; Rac1 ${ }^{\mathrm{KO} / \mathrm{CO}}$ embryos. For determination of hair cell number, consecutive $100 \times$ images of the entire OC stained with
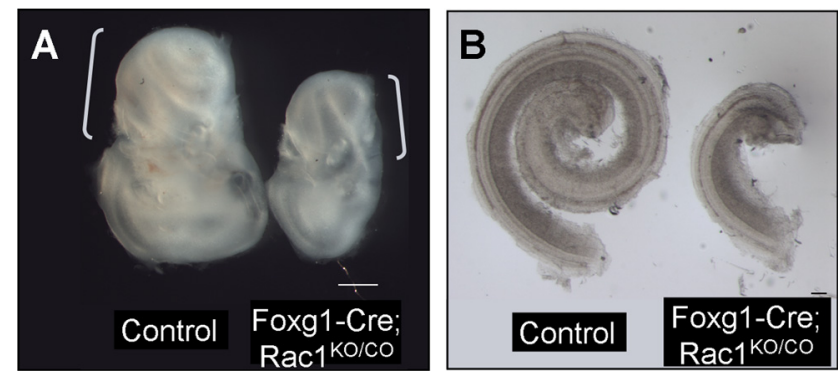

Figure 1. Rac1 mutant cochleae are severely shortened. A, Temporal bones of Foxg1-Cre; Rac ${ }^{K O / C O}$ mice display abnormal morphology at E18.5. The cochlea is at the top (brackets). $B$, Foxg1-Cre; Rac $1^{K O / C O}$ mice have a shortened cochlea of normal width compared to littermate controls at E18.5. Controls: $4870 \pm 320 \mu \mathrm{m}(n=6)$; Rac1 mutants: $2040 \pm 100 \mu \mathrm{m}(n=4) ;$ $p<0.0001$. Scale bars: $\boldsymbol{A}, 500 \mu \mathrm{m} ; \boldsymbol{B}, 100 \mu \mathrm{m}$.

phalloidin and/or myosin VI were obtained on a Zeiss AxioImager Z1 upright microscope and the number of hair cells counted. OC length was determined on $10 \times$ images of the OC. For quantitation of hair bundle defects, three mutants with a total of 622 hair cells, and four littermate controls with a total of 945 hair cells were analyzed from the basal region of the cochlea at E18.5. Phalloidin- and acetylated tubulin-stained hair cells were classified as having a normal, split, flat, or generally deformed bundle morphology, and also as having a normal, off-centered (relative to the hair bundle), or absent/poorly formed kinocilium. Mean \pm SD is given. Statistical probability was measured using Student's $t$ test. For quantitation of hair bundle orientation, hair cells from the basal region of three mutant and three littermate control cochleae were analyzed at E18.5. Orientation was measured on a total of 268 mutant and 268 control cells (60 inner hair cells and 208 outer hair cells) using ImageJ software. The orientation of a line drawn straight through the center of the bundle relative to a line drawn perpendicular to the pillar cells was used to determine bundle orientation. Bundles aligned with the perpendicular line and oriented toward the lateral border of the cochlear duct were assigned an orientation of $0^{\circ}$. Due to the kinocilium defects in the Racl mutant, orientation was estimated based upon phalloidin staining only. Mutant cells with deformed bundles lacking a discernable orientation were not included in the analysis.

Scanning electron microscopy. For scanning electron microscopy (SEM) analysis, inner ears from E18.5 mice were dissected in PBS and fixed in $4 \%$ paraformaldehyde with $2.5 \%$ glutaraldehyde overnight at $4^{\circ} \mathrm{C}$. Cochleae were then dissected out of the temporal bone, postfixed in $1 \%$ osmium tetroxide, and dehydrated through a graded ethanol series. Specimens were then critical point dried, mounted on metal studs, and sputter coated with gold. Samples were examined on a JEOL 6400 scanning electron microscope at $20 \mathrm{kV}$.

Organotypic cochlear explant cultures. Cochlear explants from Racl mutants and littermate controls were established at E18.5. Briefly, cochleae were dissected in HEPES-buffered HBSS (Invitrogen), and the developing $\mathrm{OC}$ was exposed. Cochleae with attached stria vascularis were established on coverslips coated with Cell Tak (BD Biosciences). Explants were then maintained for $4 \mathrm{~d}$ in vitro (equivalent of P3) in DMEM/F-12 (Invitrogen) supplemented with N2 (Invitrogen) and penicillin (Sigma). To assess FM1-43 uptake, samples were treated with $5 \mu \mathrm{M}$ FM1-43 (Invitrogen) for $10 \mathrm{~s}$ as previously described (Lelli et al., 2009). For quantitation of hair bundle defects in Rac1 explants, a total of 499 Rac1 mutant hair cells and 325 control hair cells from three independent experiments were analyzed from the midbasal region of the cochlea at the equivalent of P3. Phalloidin-stained hair cells were classified as having a normal, split, flat, or generally deformed bundle morphology. Mean $\pm \mathrm{SD}$ is given. Statistical probability was measured using Student's $t$ test. For PAK inhibition experiments, cochlear explants from CD1 mice were established either on E15.5, E16.5, or E17.5, and treated on the following day (equivalent of E16.5, E17.5, and E18.5, respectively) with vehicle (DMSO) or the PAK inhibitor IPA-3 (Calbiochem). Six hours after drug application, media were replaced with drug-free media. After 4 or $5 \mathrm{~d}$ in vitro (equivalent of P2), explants were fixed with $4 \%$ PFA and processed 

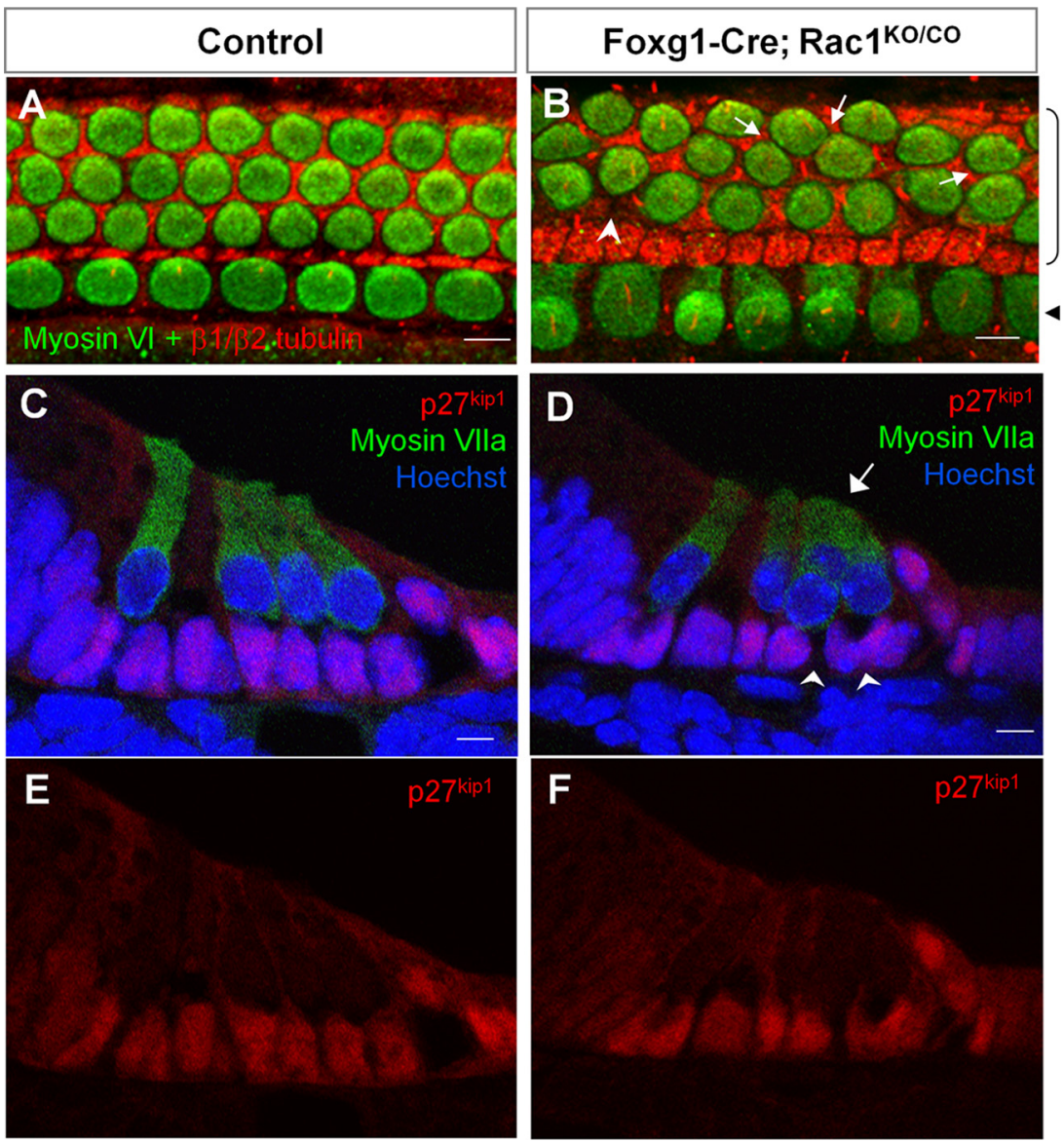

Figure 2. Rac1 is critical for organ of Corti cellular organization. $A, B$, Confocal images from the basal region of control $(A)$ and Foxg 1-Cre; Rac ${ }^{\mathrm{KO} / \mathrm{CO}}$ mutant (B) cochleae at E18.5 stained for the support cell marker $\beta 1 / \beta 2$ tubulin (red) and the hair cell marker myosin VI (green). The alternating hair cell and support cell pattern appears disrupted in the mutant with some hair cells in direct contact (arrows), support cells in direct contact (arrowhead), and jumbled hair cell rows. Mutant hair cells are also misshapen and variable in size. The black bracket and arrowhead indicate outer and inner hair cell rows, respectively. $C-F$, Confocal images of cross sections from the midbasal region of control $(\boldsymbol{C}, \boldsymbol{E})$ and Foxg1-Cre; $R a c 1^{K o / C O}$ mutant $(\boldsymbol{D}, \boldsymbol{F})$ cochleae at E18.5 stained for the support cell marker p27 $7^{\mathrm{kip} 1}$ (red), the hair cell marker myosin VIlla (green), and Hoechst (blue) to label cell nuclei. Cellular disorganization within the apical-basal plane of the Rac 1 mutant epithelium is readily apparent with some hair cells located directly over top of other hair cells (arrow) and irregular spacing between support cell nuclei (arrowheads). The Rac 1 mutant epithelium is also thinner than controls, and both hair cell and support cell nuclei exhibit abnormal morphology. Scale bars: $A-F, 5 \mu \mathrm{m}$.

for acetylated tubulin and phalloidin staining. For quantitation of hair bundle defects in IPA-3-treated explants, a total of 514 hair cells (DMSO control), 280 hair cells (5 $\mu \mathrm{M}$ IPA-3), and 533 hair cells (10 $\mu \mathrm{M}$ IPA-3) from three independent experiments were analyzed from the midbasal region of the cochlea, and bundle morphology was scored as described above.

\section{Results}

Conditional inactivation of Rac1 in the developing inner ear Of the three mammalian Rac family members, Racl is ubiquitously expressed, whereas Rac2 and Rac3 are restricted to hematopoietic and neuronal cells, respectively (Haataja et al., 1997; Glogauer et al., 2003). Both Racl and Rac3 transcripts are present in the developing cochlea (supplemental Fig. $1 A$, available at www.jneurosci.org as supplemental material). To determine Rac protein distribution in the OC, we performed immunostaining using an anti-Racl antibody from BD Biosciences that recognizes all three Rac family members (supplemental Fig. $1 B$, available at www.jneurosci.org as supplemental material). At both E16.5 and E18.5, Rac proteins were present in both sensory hair cells and support cells (e.g., Deiters', pillar, inner phalangeal) along the entire cochlear spiral (supplemental Fig. $1 C-F$, available at www.jneurosci.org as supplemental material). In hair cells, Rac staining was particularly prominent in the nascent hair bundles, delineating the entire length of the stereocilia as well as the kinocilium. In support cells, we observed strong Rac staining in the actin-rich microvilli. Thus, their expression pattern during the first phase of stereocilium elongation (Frolenkov et al., 2004; Petit and Richardson, 2009) suggests a possible role for Rac proteins in the development of the auditory sensory epithelium and hair bundle. Since Rac3-deficient mice are viable and fertile and have no reported inner ear phenotypes (Cho et al., 2005), we focused our functional analysis on Racl.

Rac1 knock-out mice die around E8 during embryonic development (Sugihara et al., 1998). Therefore, to assess the in vivo function of Racl during inner ear development, we used a conditional $R a c 1$ allele $\left(\mathrm{Racl}^{\mathrm{CO}}\right)$ that contains loxP sites flanking exon 1 and the transcriptional start site of the Racl gene (Glogauer et al., 2003). Cre-mediated recombination between the loxP sites has been shown to result in deletion of this region thereby eliminating Rac1 protein expression (Glogauer et al., 2003; Chen et al., 2007). To inactivate Racl in the entire otic epithelium, we used the Foxg1-Cre strain, in which the Cre recombinase gene is targeted to the Foxg1 locus, resulting in Cre expression in the early otocyst from E8.75 (Hébert and McConnell, 2000). We also used a $R a c 1$-null allele $\left(R a c 1^{K O}\right)$ that was derived from the $\mathrm{Racl}^{\mathrm{CO}}$ allele by germline Cre expression (Gu et al., 2003). To generate Racl mutants, we crossed Foxg1-Cre; $\mathrm{Racl}^{\mathrm{KO} /+}$ males to $\mathrm{Rac1} \mathrm{CO}^{\mathrm{COO}}$ females to obtain Foxg1-Cre; Rac1 ${ }^{\mathrm{KO} / \mathrm{CO}}$ progeny. Littermates were used as controls. Although no Foxg1$\mathrm{Cre}$; Rac1 ${ }^{\mathrm{KO} / \mathrm{CO}}$ mice survived after birth [most likely due to Cre expression outside the inner ear (Hébert and McConnell, 2000; Chen et al., 2007) ], Foxg1-Cre; Rac1 ${ }^{\mathrm{KO} / C O}$ embryos were present in a Mendelian ratio up to E18.5 (155/682 = 23\%, expected 25\%).

\section{Racl is required for cochlear morphogenesis}

At E18.5, the temporal bones from Foxg1-Cre; Rac1 ${ }^{\mathrm{KO} / \mathrm{CO}}$ (referred to as Racl mutant hereafter) embryos appeared highly dysmorphic, and this phenotype was fully penetrant in all mutants analyzed. At a gross level, the temporal bones were much smaller and abnormally shaped compared to littermate controls (Fig. 1A). In particular, the otic capsule surrounding the vestibular apparatus had a narrow and pointed shape, suggestive of semicircular canal defects. In this study, we focused our analysis on the cochlear phenotypes. At E18.5, although a cochlea was present, it was dramatically reduced in length [controls: $4870 \pm$ $320 \mu \mathrm{m}(n=6)$; mutants: $2040 \pm 100 \mu \mathrm{m}(n=4)]$ (Fig. $1 B)$. The cochlea spiral formed one-half to three-quarters of one turn versus one and three-quarters turns in the controls. Of note, the width of the cochlear duct was normal, and we did not detect 
supernumerary rows of hair cells along the cochlea. We quantified the number of hair cells by myosin VI and/or phalloidin staining. The total number of hair cells present in the OC of Rac1 mutant embryos was significantly reduced compared to littermate controls [controls: $2437 \pm$ $49(n=5)$; mutants: $1032 \pm 69(n=5)]$. This reduction in hair cell number directly correlated with the decreased length of the OC, indicating a relatively normal hair cell density.

\section{Rac1 is critical for organ of Corti cellular organization}

Based on immunostaining of hair cell and support cell markers, differentiation of hair cells and support cells in Racl mutants was essentially normal (Fig. 2; supplemental Fig. 2A-F, available at www. jneurosci.org as supplemental material; and data not shown). This suggests that $\mathrm{Racl}$ is not required for cell fate determination in the OC. In addition, three rows of outer hair cells and one row of inner hair cells were mostly present throughout the mutant cochlea. However, cellular disorganization in the Rac1 mutant OC can be detected as early as E15.5; by E18.5, the invariant mosaic pattern of hair cells interdigitated with support cells with regular spacing was abnormal in Rac1 mutants (Fig. 2A,B; supplemental Fig. $2 A-H$, available at www.jneurosci.org as supplemental material). In many cases, pairs of hair cells appeared to be in contact with each other (Fig. $2 B$, arrows). Similarly, the apical extensions of two support cells often appeared to be in contact (Fig. $2 B$, arrowhead). Moreover, both the shape and the size of hair cells were irregular in Racl mutants. The apical surface of many hair cells often appeared oblong, in contrast to a uniformly round appearance in controls (Fig. 2B).

Cellular disorganization was also apparent in cross sections of the OC along the apical-basal polarity axis (Fig. $2 C-F$ ). In control cross sections, the hair cell nuclei were aligned at a uniform distance from the luminal surface of the epithelium. In contrast, in Racl mutants the hair cell nuclei were often found at variable distances from the luminal surface (Fig. $2 D$, arrow). Moreover, because of disrupted spacing of the cellular mosaic, more than four hair cells were frequently present in cross sections of Rac1 mutants, in contrast to control cross sections, which invariably have four hair cells. We also observed irregular spacing between support cell nuclei in Rac1 mutants (Fig. 2D, arrowheads). The shape of the nuclei of both hair cells and support cells was also irregular. Finally, the height of the hair cells and support cells in Racl mutants appeared shorter than controls, and as a result the overall thickness of the OC was thinner in Racl mutants compared to controls. Together, these data suggest that Rac1 is critical for cellular patterning in the OC.
To determine whether cellular disorganization in the Rac1 mutant OC resulted from defective cell-cell adhesion (Jaffe and Hall, 2005), we examined the localization of E-cadherin and $\beta$-catenin, components of the adherens junction (supplemental Fig. 3, available at www.jneurosci.org as supplemental material). At E18.5, E-cadherin and $\beta$-catenin are localized on the basolateral membranes of both hair cells and support cells. In Racl mutants, there are no overt changes in the distribution of either E-cadherin or $\beta$-catenin, suggesting that Rac1 is not required for the recruitment of these junctional proteins to cellular contacts.

\section{PCP phenotypes in Rac1 mutants}

Immunostaining of Rac1 mutant hair bundles at E18.5 revealed both bundle misorientation and structural deformation (see Fig. 5 ). The orientation defects were observed in all hair cell rows and in both structurally normal and abnormal bundles. Overall, the angle measurements of misoriented bundles were mostly within $50^{\circ}$, with outer hair cell rows 2 and 3 more affected than other rows (supplemental Fig. 4, available at www.jneurosci.org as supplemental material). 


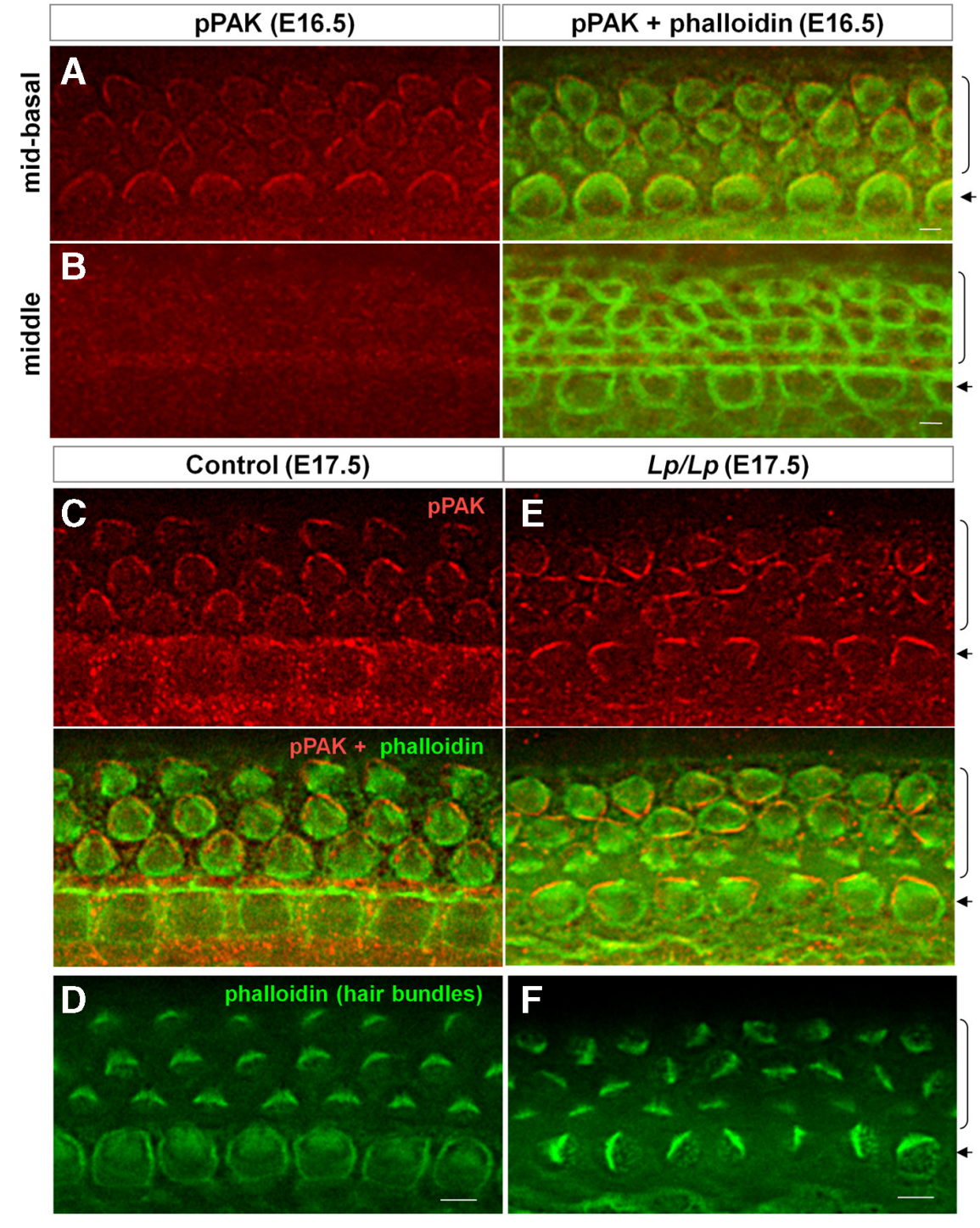

Figure 4. Phospho-PAK localization during planar polarization in the $O C . A, B$, In wild type, localization of pPAK on the lateral membranes of hair cells is detected in the midbasal $(\boldsymbol{A})$ but not in the middle $(\boldsymbol{B})$ or apical regions of the $0 \mathrm{C}$ at E16.5. Red, pPAK; green, phalloidin. The overlay is shown on the right. $\boldsymbol{C}-\boldsymbol{F}, \mathrm{pPAK}$ staining in control $(\boldsymbol{C}, \boldsymbol{D})$ and $L p / L p$ mutant $(\boldsymbol{E}, \boldsymbol{F}) 0 \boldsymbol{O}$ at E17.5. In controls, pPAK is asymmetrically localized on the lateral membranes of hair cells, corresponding to hair bundle orientation (compare $\boldsymbol{C}$ to $\boldsymbol{D})$. In $L p / L p$ mutants, the pPAK crescent still forms but is misoriented, correlating with bundle misorientation defects (compare $\boldsymbol{E}$ to $\boldsymbol{F}$ ). Red, pPAK; green, phalloidin. The overlay is shown below the pPAK staining. Panels $\boldsymbol{D}$ and $\boldsymbol{F}$ are phalloidin staining from a Z-plane apical to $\boldsymbol{C}$ and $\boldsymbol{E}$, respectively, showing the corresponding hair bundles. Brackets and arrowheads indicate outer and inner hair cells, respectively. Scale bars: $\boldsymbol{A}, \boldsymbol{B}, 2 \mu \mathrm{m} ; \boldsymbol{C}-\boldsymbol{F}, 5 \mu \mathrm{m}$.

Bundle orientation, a readout for hair cell PCP, is regulated by a PCP pathway with both conserved and novel components (Rida and Chen, 2009). The first sign of planar polarization of hair cells is the migration of the kinocilium from the center to the lateral edge of the hair cell apex, which starts at the base of the cochlea at E16.5 (Montcouquiol et al., 2003). To determine whether Rac1 regulates the initial establishment of hair cell PCP, we scored the location of the kinocilium in the basal region of the cochlea at E16.5. In the Rac1 mutant, most kinocilia were positioned toward the hair cell lateral edge, similar to controls (supplemental Fig. $2 I-L$, available at www.jneurosci.org as supplemental material). Thus, establishment of PCP appears to be normal in the Rac1 mutant.

A hallmark feature of PCP proteins is that they become asymmetrically localized during signaling. In the OC, for example, Dishevelled-2 appears to be enriched on the lateral side of the hair cell membranes, whereas Vangl2 and Frizzled-3 (Fz3) are located on the medial side (Wang et al., 2005, 2006a,b; Montcouquiol et al., 2006; Etheridge et al., 2008). Asymmetric membrane localization of PCP proteins requires cell-cell interactions (Adler, 2002; Rida and Chen, 2009). Because the normal pattern of cellcell interaction is disrupted in the Rac1 mutant OC (Fig. 2; supplemental Fig. $2 A-H$, available at www.jneurosci.org as supplemental material), we examined whether the localization of the PCP protein $\mathrm{Fz} 3$ was affected. In controls, at E17.5 in the midbasal region of the cochlea, Fz3 staining is already medially enriched, forming a characteristic line abutting the medial border of hair cell rows (Fig. 3A). By E18.5, asymmetric Fz3 staining is even more apparent, forming a tight crescent on the medial side of hair cell membranes, as previously reported (Montcouquiol et al., 2006; Wang et al., 2006b) (Fig. 3C). Fz3 was also present on cell membranes around the pillar cells. In contrast, in E17.5 Rac1 mutants, although Fz3 still appeared to be partially localized to cell membranes, it was no longer uniformly enriched on the medial side (Fig. 3B). By E18.5, the membrane crescent of $\mathrm{Fz} 3$ was not detectable in the mutant (Fig. 3D). However, membrane staining around the pillar cells remained normal. These results suggest that Racl is required for asymmetric distribution of Fz3 in the developing OC. Together with the fact that the Racl mutation has no apparent effect on kinocilium migration, an early event during planar polarization, these results are consistent with a role of Racl in the maintenance, rather than the initial establishment of PCP in the developing OC.

Previously Racl was identified as a downstream effector of PCP signaling regulating convergent extension during gastrulation (Habas et al., 2003). To test whether Rac1 activity is regulated by PCP signaling in the OC, we focused on PAKs, which are well known downstream effectors of Rac that regulate cytoskeletal dynamics (Bokoch, 2003). We first examined the pattern of PAK activation in the wild-type OC, using a phospho-PAK (pPAK) antibody that specifically detects a phosphoepitope present in activated PAK. At E16.5, during the initial establishment of PCP, pPAK appeared to be enriched on the lateral membranes of hair cells in the basal to midbasal region but not yet in the more apical regions of the cochlea (Fig. 4A,B). Concomitant with the wave of hair cell differentiation along the cochlear duct, the asymmetric membrane localization of pPAK spread toward the cochlear apex by E17.5. In the midbasal region at E17.5, the pPAK crescent correlated perfectly with hair bundle orientation (Fig. $4 C, D$ ). Next, we examined pPAK localization in the $L p$ mice, mutant for the conserved core PCP gene, vangl2 (Montcouquiol et al., 2003). In E16.5 Lp mutants, while pPAK was still asymmetrically localized 
on apical membranes, it was misoriented relative to the medial-lateral polarity axis (data not shown). Similarly, in E17.5 Lp mutants, the pPAK crescent was present but misoriented, which correlated perfectly with the misoriented hair bundle (Fig. $4 E, F$ ). These results suggest that the pPAK localization is a novel readout for PCP in hair cells, and that the PCP pathway may spatially regulate PAK activity.

\section{Racl is critical for hair bundle morphogenesis}

We closely examined hair bundle structural defects using immunostaining (Fig. 5) and SEM (Fig. 6). Normal hair bundles have intrinsic structural polarity: stereocilia have graded heights, forming a crescent with the kinocilium centered next to the tallest stereocilia (Figs. 5A, 6A). In contrast, in Racl mutants, many hair bundles exhibited a variety of structural defects: stereocilia formed either flat, straight rows (flat bundles) (Fig. 6D-F) or multiple clumps of stereocilia within the same cell (split bundles) (Fig. 6G,H), or had other abnormal shapes (generally deformed bundles) (Fig. $6 I, J$ ). In flat bundles, stereocilia either appeared uniform in height across the row (Fig. 6D), or were organized in a wavy line or even a slight inverted crescent shape, with the taller stereocilia at the edges of the bundle (Fig. $6 E, F)$. Hair bundles defects were accompanied by abnormalities of the kinocilium. In many flat bundles, the kinocilium was located at one end of the bundle (offcenter), rather than in the center (Figs. $5 B$, $6 B, D-F)$. Within the split bundles, the kinocilium was usually found centered within one group of stereocilia (Figs. $5 B$, $6 \mathrm{~B}, \mathrm{G}, H)$. Moreover, the kinocilium in a fraction of mutant cells was either absent or poorly formed, as assessed by acetylated tubulin staining (Fig. 5B). Of note, in Rac1 mutants, although the positioning of the kinocilium relative to the stereociliary bundle was often abnormal, the migration of the kinocilium to the lateral edge of the hair cell apex was essentially normal. Overall, 64\% of Racl mutant hair cells scored from the basal region of the cochlea displayed some form of hair bundle disorganization (Fig. 5C,D). Together these observations demonstrate a requirement of Rac1 during the early phase of bundle morphogenesis.

To investigate a potential role of Racl in regulating stereocilium elongation, we tested whether Racl regulates the localization of known actin regulatory proteins that control stereocilium elongation. In particular, the espin actin-bundling protein, mutated in jerker mice, can drive stereocilium elongation when overexpressed and is localized throughout the stereocilia (Rzadzinska et al., 2005; Sekerková et al., 2006). Myosin XVa and whirlin, mutations in which result in abnormally short stereocilia, are required for the differential elongation of the stereocilia and are localized to the tips of stereocilia (Belyantseva et al., 2005). Myosin VIIa, which is mutated in shaker-1 mice and human patients with Usher syndrome $1 \mathrm{~B}$, is localized to the cuticular plate, the tips of the stereocilia and the kinocilium (Lefèvre et al., 2008). We observed no overt changes in the localizations of these proteins in Rac1 mutants at E18.5 (supplemental Fig. 5, available at www.jneurosci.org as supplemental material), suggesting that $\mathrm{Racl}$ is not required for the localization of these key hair bundle proteins to the nascent hair bundle.

\section{Conditional inactivation of Rac1 in the developing inner ear by Pax2-Cre}

In Foxg1-Cre mice, the Cre recombinase is targeted to the Foxg1 locus, replacing the Foxg1 coding sequences and thereby resulting in Foxg1 haploinsufficiency (Hébert and McConnell, 2000). The Foxg1 gene itself also regulates inner ear morphogenesis (Pauley et al., 2006). To exclude the possibility that the Foxg1-Cre; $\mathrm{Racl}^{\mathrm{KO} / \mathrm{CO}}$ mutant phenotype is due in part to Foxg1 haploinsufficiency, we used an independent Cre deleter strain to inactivate Rac1 in the developing inner ear. Pax2-Cre is a BAC transgenic line that expresses Cre throughout the early otocyst (E8.75) (Ohyama and Groves, 2004). We generated Pax2-Cre; $\mathrm{Racl}^{\mathrm{CO} / \mathrm{CO}}$ embryos and analyzed their inner ears at E17.5 [we were unable to recover mutants at E18.5, probably due to Cre expression outside the inner ear (Ohyama and Groves, 2004)]. 

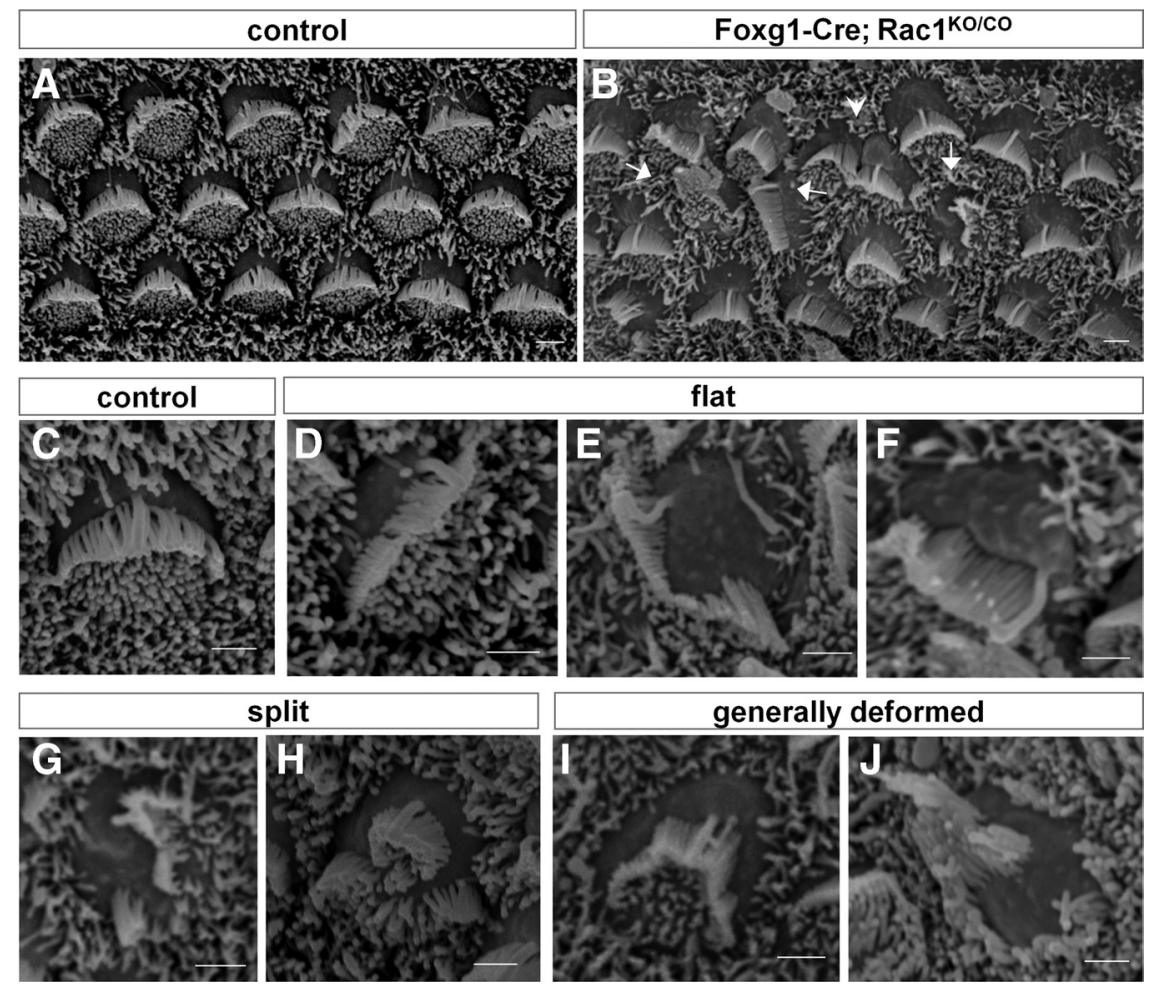

split
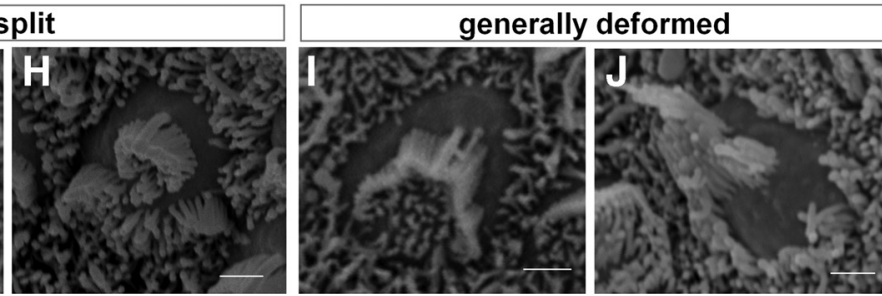

Figure 6. SEM analysis of Foxg1-Cre; Rac $7^{K O / C O}$ organ of Corti. Scanning electron micrographs of outer hair cells from the basal region of control $(\boldsymbol{A}, \boldsymbol{C})$ and Foxg1-Cre; Rac1 ${ }^{K O / C O}(\boldsymbol{B}, \boldsymbol{D}-\boldsymbol{J})$ cochleae at E18.5. B, In Foxg1-Cre; Rac $7^{\mathrm{KO} / \mathrm{CO}}$ embryos, the hair cells exhibit a variety of deformed and misoriented bundles, as indicated by arrows. Arrowhead points to two hair cells in direct contact, one of which appears to lack a kinocilium. $\boldsymbol{C}-\boldsymbol{J}$, High-magnification images of outer hair cells. $\boldsymbol{C}$, Wild-type hair cell. $\boldsymbol{D}-\boldsymbol{F}$, Rac mutant hair cells with flat bundles and off-center kinocilium. $\mathbf{G}, \boldsymbol{H}$, Rac 1 mutant hair cells with split bundles. $\boldsymbol{I}$, A Rac 1 mutant hair cell with a generally deformed bundle where a crescent shape is still recognizable. J, A Rac1 mutant hair cell with a generally deformed bundle that lacks any discernable organization pattern. Scale bars: $A, B, 2 \mu \mathrm{m} ;(-J, 1 \mu \mathrm{m}$.

In these embryos, we observed the full spectrum of phenotypes of Foxg1-Cre; Rac1 ${ }^{\mathrm{KO} / C O}$ embryos, including abnormally shaped temporal bones, a shortened cochlear duct, cellular organization defects within the OC, and hair bundle structural and orientation defects (supplemental Fig. 6, available at www.jneurosci.org as supplemental material). Together these data strongly support the conclusion that the phenotypes observed in Foxg1-Cre; Rac1 ${ }^{\mathrm{KO} / \mathrm{CO}}$ embryos are specific effects of Racl deletion.

\section{Progressive hair bundle fragmentation in Rac1 mutant explants}

Staircase formation and functional maturation of the hair bundle occur in the first postnatal week in mice (El-Amraoui and Petit, 2005; Lelli et al., 2009). Because Rac1 mutant embryos die at birth, we were not able to assess hair bundle maturation of these mutants in vivo. To further examine maturation of Rac1 mutant hair cells, we established cochlear explant cultures from Foxg1Cre; Rac1 ${ }^{\mathrm{KO} / \mathrm{CO}}$ mutant mice at E18.5 and allowed them to grow for $4 \mathrm{~d}$ in vitro (equivalent of $\mathrm{P} 3$ ). We then examined the stereociliary bundles by immunostaining and SEM analysis. In both mutant and control cultures, extra rows of outer hair cells were frequently observed, as has been observed previously in cochlear explants (Montcouquiol and Kelley, 2003). Nevertheless, in control cultures the hair bundles had normal morphology and orientation (Fig. 7A,D,F; supplemental Fig. 7C, available at www. jneurosci.org as supplemental material). In mutant explants, on the other hand, $86 \%$ of hair bundles appeared dysmorphic. The severity of bundle disorganization varied among cultures, examples of which are shown in Figure 7, $B$ (moderate) and $C$ (severe).
In severe cases, the majority of cells had fragmented (split) bundles detached from the kinocilium. Flat and other types of abnormal bundles were observed less frequently (Fig. 7G-K; supplemental Fig. 7C, available at www.jneurosci.org as supplemental material). Consistent with the normal localization of bundle elongation proteins in Racl mutants (supplemental Fig. 5, available at www.jneurosci.org as supplemental material), the stereocilia in mutant explants still exhibited graded heights despite the fragmentation defects (Fig. $7 G-K$ ), suggesting that formation of the staircase can proceed in the absence of Rac1.

To further evaluate functional maturation of Rac1 mutant hair cells, we assayed for FM1-43 uptake in explants. FM1-43 is a fluorescent styryl dye that can be taken up by hair cells through their mechanotransduction channels, which develop postnatally in the mouse cochlea, in a gradient from base $(\sim \mathrm{P} 1)$ to apex $(\sim \mathrm{P} 3)$ (Lelli et al., 2009). Rac1 mutant explants exhibited similar levels of FM1-43 uptake compared to control explants, consistent with the presence of transduction channels in Rac1 mutant hair cells (supplemental Fig. 7A,B, available at www. jneurosci.org as supplemental material). Together, these results argue that, during hair bundle maturation, Racl is specifically required for hair bundle cohesion, but is dispensable for differential elongation of the stereocilia and the acquisition of the mechanotransduction channels.

\section{Rac1 regulates bundle cohesion via PAK}

To investigate the mechanisms by which Racl regulates the cohesion of the developing hair bundle, we first examined whether pPAK localization is altered in Racl mutants. At E17.5, while a robust pPAK crescent was observed in control OC (Fig. 8A), in Rac1 mutants, a significant fraction of hair cells showed abnormal pPAK staining. In some hair cells, the membrane localization of pPAK was diffused or diminished (Fig. $8 B$, arrow). In others, the crescent of pPAK staining lost its lateral orientation (Fig. $8 B$, open arrowheads). By E18.5, in controls, in addition to the membrane localization (Fig. $8 C$ ), pPAK was enriched in a region surrounding the lateral side of the hair bundle base and the kinocilium insertion site, and also on some stereocilia (Fig. $8 E, G)$. In this region, which was largely devoid of $\alpha$-spectrin, a component of the cuticular plate, pPAK staining partially overlapped with microtubules (supplemental Fig. 8, available at www. jneurosci.org as supplemental material). In E18.5 Rac1 mutants, similar to E17.5, membrane staining of pPAK was diffused in some hair cells (Fig. 8D). While some cells had normal pPAK staining around the hair bundle base, in others, particularly those with deformed bundles, pPAK staining around the bundle base became diffused and disorganized (Fig. 8F,H,I). The staining pattern of pPAK supports the hypothesis that PAK acts downstream of Rac to regulate hair bundle morphogenesis.

To test this hypothesis, we applied a specific chemical inhibitor of PAK, IPA-3 (Deacon et al., 2008), to mouse embryonic 

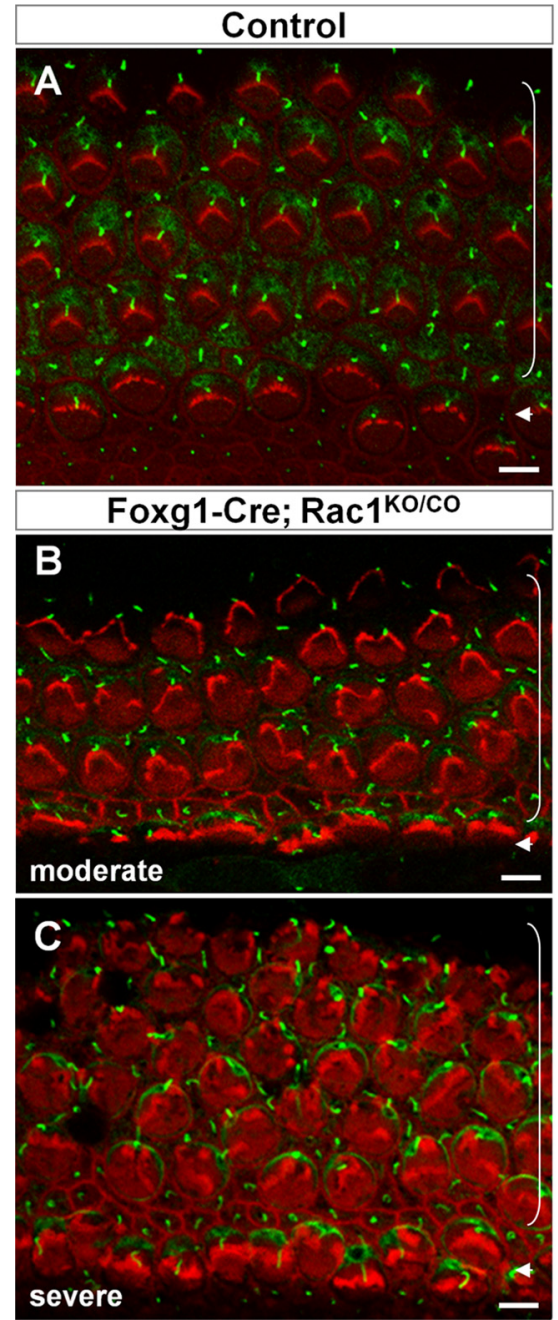
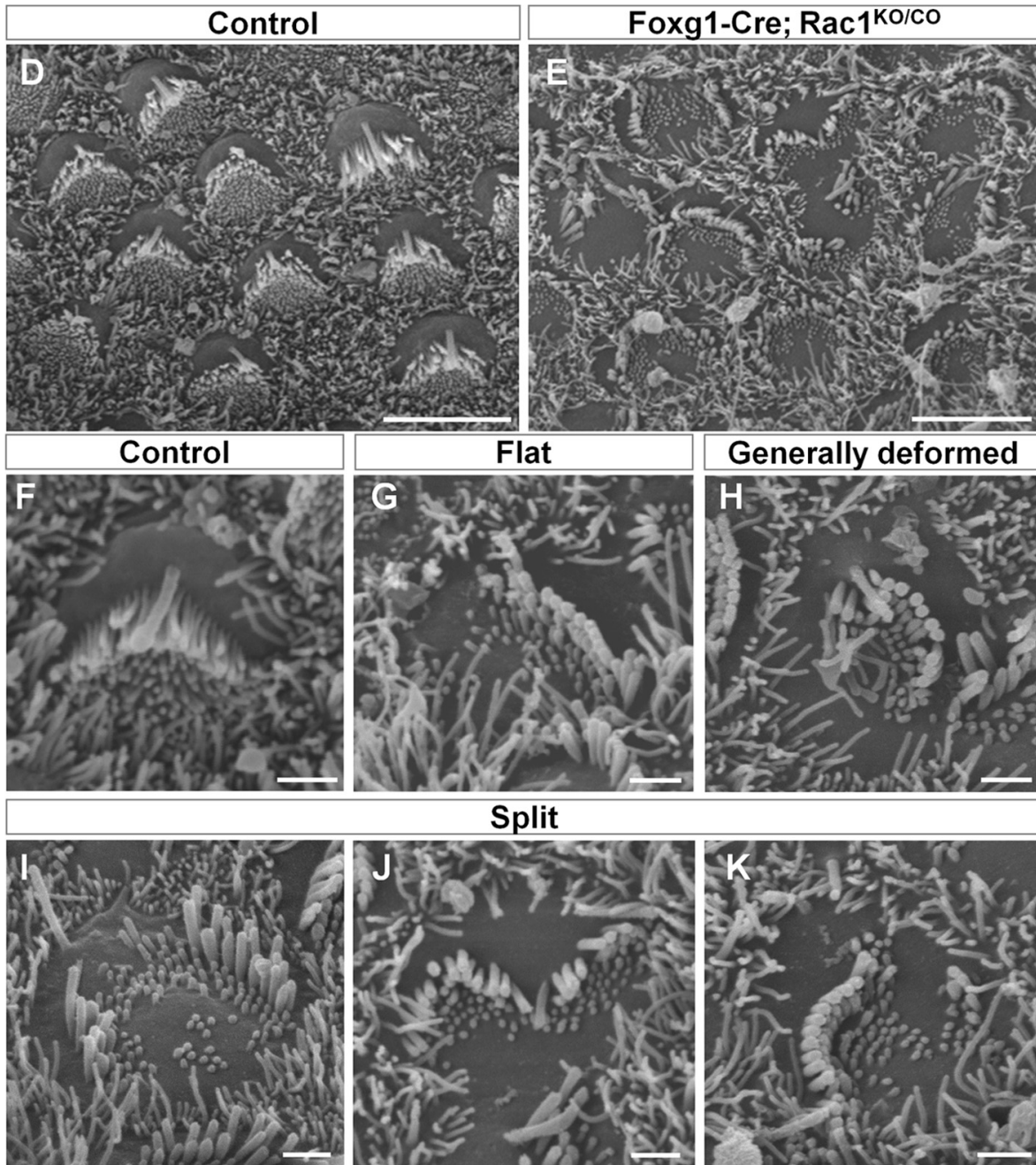

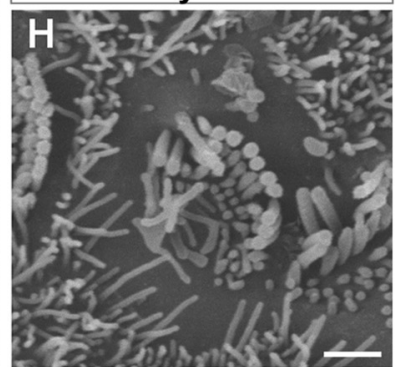

\section{Split}
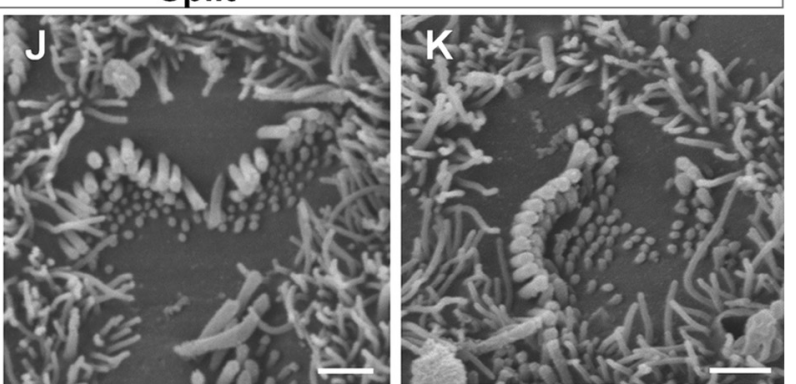

Figure 7. Progressive fragmentation of Rac1 mutant hair bundles in vitro. Cochlear explants from control ( $\boldsymbol{A})$ and Foxg 1-Cre; Rac $1^{K 0 / C O}$ mutants ( $\left.\boldsymbol{B}, \boldsymbol{C}\right)$ were established at E18.5 and grown for $4 \mathrm{~d}$ in vitro (equivalent of P3). Cultures were then fixed and stained for phalloidin (red) and acetylated tubulin (green). $A$, Stereociliary bundles in controls continued to mature normally and maintain their characteristic crescent shape and orientation. B, C, In the Rac 1 mutant, hair bundle morphology further deteriorated compared to E18.5. Virtually 100\% of hair cells in the Rac 1 mutant explants were deformed by varying degrees. The severity of hair bundle deformation varied between mutant cultures, ranging from moderate $(\boldsymbol{B})$ to severely disorganized $(\boldsymbol{C})$. Brackets and arrowheads indicate outer and inner hair cells, respectively. D, E, Scanning electron micrographs of P3 equivalent outer hair cells from control (D) and Foxg 1-Cre; Rac $7^{K 0 / C O}$ mutant (E) explants. $\boldsymbol{F}-\boldsymbol{K}$, High-magnification images of P3 equivalent outer hair cells, explanted atE18.5. F, A control hair cell. G-K, Rac $\mathbf{I}$ mutant hair cells. $\mathbf{G}$, A flat bundle. $\boldsymbol{H}$, A generally deformed bundle. I- $\boldsymbol{K}$, Split bundles. Note that the staircase pattern of differentially elongated stereocilia is still present in the mutant bundles. Scale bars: $\boldsymbol{A}-\boldsymbol{E}, 5 \mu \mathrm{m} ; \boldsymbol{F}-\boldsymbol{K}, 1 \mu \mathrm{m}$.

cochlear explants at different developmental stages and examined the effect of blocking PAK signaling on hair bundle morphology. Strikingly, IPA-3 treatment at the equivalent of E18.5 resulted in hair bundle fragmentation and kinocilium mispositioning in a dosage-dependent manner (Fig. $8 \mathrm{~J}-L$; supplemental Fig. $7 D$, available at www.jneurosci.org as supplemental material), phenocopying the bundle defects of Racl mutant explants (Fig. 7, supplemental Fig. $7 C$, available at www.jneurosci.org as supplemental material). Specifically, treatment with $10 \mu \mathrm{M}$ IPA-3 resulted in $89 \%$ dysmorphic bundles, the majority of which were split (supplemental Fig. 7D, available at www.jneurosci.org as supplemental material). To determine the critical period of PAK signaling for hair bundle cohesion, we also treated explants at the equivalent of E16.5 or E17.5 with IPA-3. Treatment at E16.5 and E17.5 caused very slight and mild bundle deformation, respectively (data not shown). Therefore, we conclude that Rac-PAK signaling is required for the cohesion of the developing hair bundle during the late phase of bundle morphogenesis.

\section{Discussion}

Many of the deafness genes implicated in hair bundle morphogenesis were originally identified through genetic analysis of hearing-impaired individuals or mouse mutants (Friedman et al., 2007; Leibovici et al., 2008). These genetic studies have provided great insights into the mechanisms underlying normal hair cell development and function, as well as the pathophysiology of deafness and balance disorders. However, the function of essential genes in hair cell development, such as ubiquitous or global regulators of the actin cytoskeleton, is still poorly understood due to the early lethality associated with loss-of-function mutations in these genes. Our results in this study demonstrate a requirement of Racl, a central regulator of actin dynamics, in cochlear morphogenesis and hair bundle formation, and shed new light on the exquisite genetic control of hair bundle morphogenesis.

The pleiotropic effects of Racl deletion indicate that Racl participates in multiple developmental pathways to coordinate cochlear epithelial morphogenesis. Racl mutants have a severely 


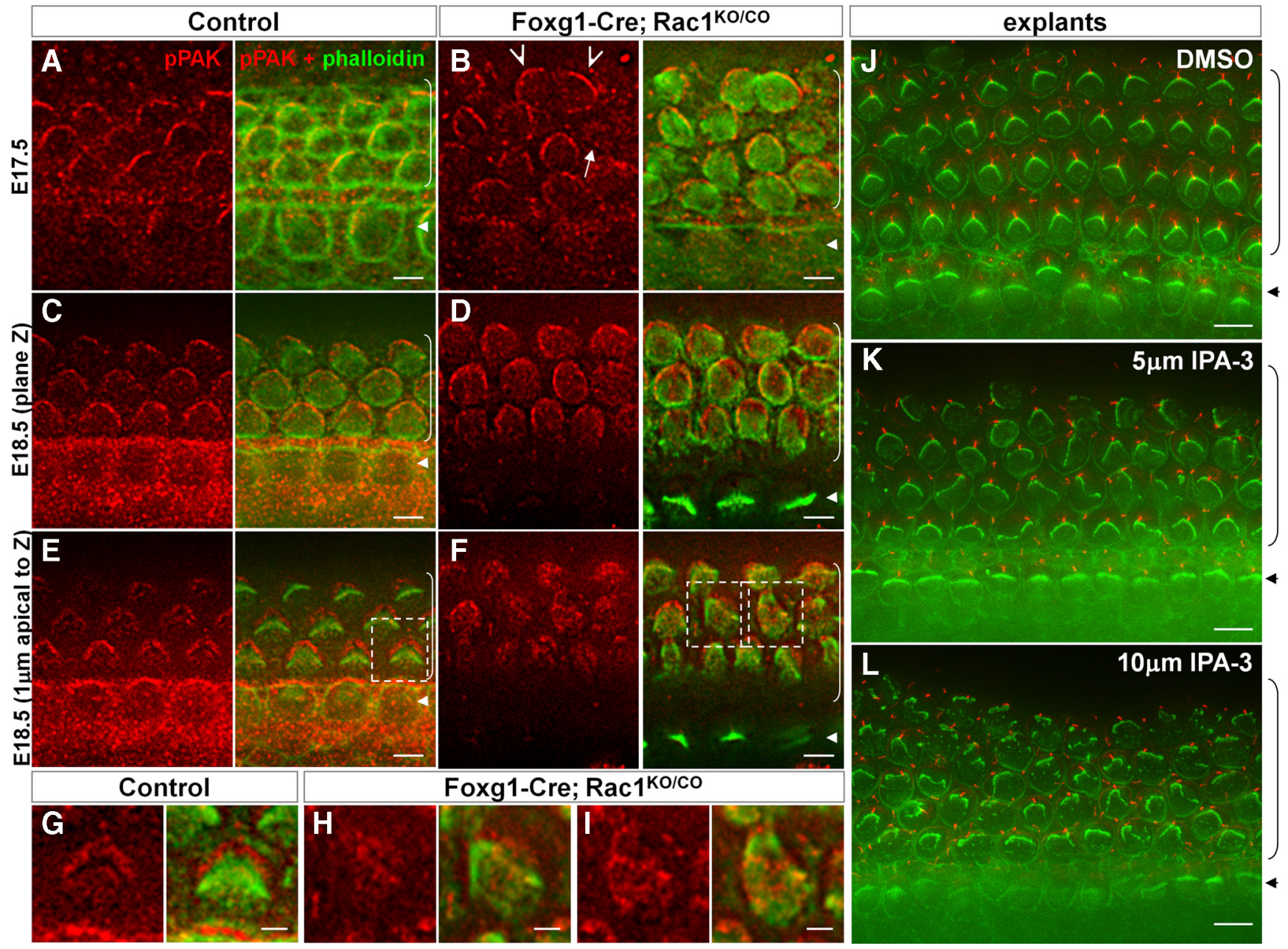

Figure 8. Rac1 regulates bundle morphogenesis via PAK. A-I, Rac1 regulates phospho-PAK localization in the OC. Red, pPAK; green, phalloidin. At E17.5, pPAK staining is on the lateral membranes of hair cells in controls $(\boldsymbol{A})$ and is reduced (arrow) or misoriented (arrowheads) in the Rac 1 mutant $(\boldsymbol{B})$. In E18.5 controls, pPAK is localized on lateral membranes $(\boldsymbol{C})$ and in a region adjacent to the kinocilium insert site and the base of the hair bundle $(\boldsymbol{E})$. In Rac 1 mutants, staining on the membrane $(\boldsymbol{D})$ and around the hair bundle base $(\boldsymbol{F})$ appears diffused and disorganized in some hair cells. $\mathbf{G}-\boldsymbol{I}$, Close-up images of single $Z$ sections of control $(\boldsymbol{G})$ and Rac 1 mutant $(\boldsymbol{H}, \boldsymbol{I})$ hair cells, corresponding to cells boxed in $\boldsymbol{E}$ and $\boldsymbol{F}$, respectively. Note that the normal pPAK staining around the base of the bundle $(\boldsymbol{G})$ becomes diffused and disorganized in mutant cells with deformed bundles $(\boldsymbol{H}, \boldsymbol{I})$. $\boldsymbol{J}-\boldsymbol{L}$, Inhibition of PAK activity in cochlear explants results in bundle fragmentation. Explants were established on E17.5 and treated on the following day with DMSO $(J)$, the PAK inhibitor IPA-3 at $5 \mu \mathrm{m}(\boldsymbol{K})$ or $10 \mu \mathrm{m}(\boldsymbol{L})$. Red, Acetylated tubulin; green, phalloidin. All images are taken from the midbasal region of the cochlea. Brackets and arrowheads indicate outer and inner hair cells, respectively. Scale bars: $A-F, 5 \mu \mathrm{m} ; \mathbf{G}-\mathbf{I}, 2 \mu \mathrm{m} ; \boldsymbol{I}-\boldsymbol{L}, 10 \mu \mathrm{m}$.

shortened cochlea with a reduced number of hair cells and support cells, consistent with an early function of Racl in specification of the OC precursor cells, which awaits further studies. Rac1 deletion also had a deleterious effect on cell-cell interactions in the OC, with abnormalities in cell shape, spacing, and arrangement. Although we did not detect gross changes in the distribution of adherens junction components, subtle defects in cell-cell adhesion and/or cell contractility may account for these phenotypes.

$\mathrm{Racl}$ is also necessary for normal PCP signaling. Racl mutants exhibited misoriented hair bundles similar to mouse PCP mutants. We found that the activity of PAK proteins, downstream effectors of Rac, is asymmetrically localized according to the PCP axis and is likely spatially regulated by PCP signaling during bundle orientation. However, we were unable to reliably examine the role of PAK in bundle orientation in vitro, as wild-type cochlear explants grown on artificial substrates often have slight orientation defects (data not shown). We also found that asymmetric localization of $\mathrm{Fz} 3$ was disrupted in Rac1 mutants, which is likely a secondary effect of epithelial/cytoskeletal disorganization. There are precedents for a role of the cytoskeleton in PCP regu- lation (Blair et al., 2006; Shimada et al., 2006; Yan et al., 2009). Together, these results support both a direct role of Rac1 as a downstream effector of the PCP pathway and perhaps an indirect role in regulating Fz3 localization via the cytoskeleton. The multiple functions of Racl in regulating PCP in the inner ear parallels those of Rhol in Drosophila, where Rhol acts both downstream and upstream of the core PCP genes (Yan et al., 2009). Our results provide further evidence that Rac GTPases are required for PCP signaling in vertebrates (Habas et al., 2003). This stands in contrast to Drosophila, where Rac genes appear to have very minor, if any, function in PCP regulation (Hakeda-Suzuki et al., 2002; Muñoz-Descalzo et al., 2007). We speculate that, like other vertebrate-specific PCP regulators, the Rac genes are co-opted by the core PCP pathway to effect complex cytoskeletal remodeling during vertebrate tissue morphogenesis.

Racl function is essential for hair bundle morphogenesis. The split bundle phenotype, where stereocilia form separate clumps on the hair cell apex, resembles the phenotypes of mice mutant for Usher syndrome type I (USH1) genes, which encode myosin VIIa, harmonin, sans, cadherin 23, and protocadherin 15 (Lefevre et al., 2008). USH1 is characterized by congenital deafness, vestib- 
ular dysfunction, and blindness caused by retinitis pigmentosa. Interestingly, Dock4, a guanine nucleotide exchange factor (GEF) for Rac1 (Lu et al., 2005), has recently been shown to localize to hair cell stereocilia, where it binds to harmonin (Yan et al., 2006). We observed no changes in myosin VIIa and harmonin localization in Rac1 mutants (supplemental Fig. 5, available at www.jneurosci.org as supplemental material; and data not shown), suggesting that Rac1 is not required for the localization of USH1 proteins. Although the function of Dock 4 in hair bundle formation is not known, it is tempting to speculate that USH1 proteins act upstream to regulate Racl activity via Dock4 during bundle morphogenesis.

Flat bundles were also frequently observed in Racl mutants at E18.5, where the kinocilium had an abnormal off-center position. This phenotype suggests that Racl regulates interactions between the kinocilium and stereocilia in the developing hair bundle. There is increasing evidence for the role of the kinocilium and its associated basal bodies as the "hair bundle organizing center" to instruct the intrinsic structural polarity of the hair bundle. Indeed, it has been reported that mouse mutants for genes implicated in human ciliopathy, such as the Bardet-Biedl syndrome, have "flattened" bundles with mispositioned kinocilium (Ross et al., 2005). Furthermore, genetic ablation of the kinocilium in the mouse leads to formation of hair bundles with a flattened morphology (Jones et al., 2008; C. Sipe and X. Lu, unpublished results). Because Rac1 mutant explants had a predominant split bundle phenotype at the equivalent of $\mathrm{P} 3$, we infer that flat bundles proceed to become fragmented. Thus, our results highlight the requirement of kinocilium-stereocilium interaction for maintenance of hair bundle integrity.

Despite bundle fragmentation, in Racl mutant explants we still observed formation of the bundle staircase and relatively normal FM1-43 uptake. These results argue that developmental pathways that regulate distinct aspects of hair bundle morphogenesis, such as hair bundle cohesion, differential elongation of the stereocilia, and acquisition of the mechanotransduction apparatus, operate independently of one another. Consistent with this idea, FM1-43 uptake occurs normally in the Snell's waltzer myosin VI mutant mouse, which displays severe bundle structural defects (Self et al., 1999). Likewise, mechanotransduction is normal in myosin XVa mutants with abnormally short stereocilia (Stepanyan et al., 2006). Nevertheless, disruption of any of the aforementioned aspects of bundle morphogenesis will disable hearing.

We identified PAK kinases as important downstream effectors of Racl during auditory hair bundle morphogenesis. Rac1 deletion appeared to reduce, rather than abolish pPAK staining. Together with the fact that some but not all Racl mutant hair cells displayed hair bundle defects, it suggests that other small GTPases may function redundantly with Racl to activate PAK signaling during bundle morphogenesis. Indeed, we found by RT-PCR analysis that, in addition to Rac1, Rac3 and the closely related Cdc42 were also expressed in the developing cochlea (supplemental Fig. $1 \mathrm{~A}$, available at www.jneurosci.org as supplemental material; and data not shown). Furthermore, to determine whether Rac1 has a similar function in vestibular hair cells, we examined Racl mutant utricles and observed essentially normal bundle morphology, FM1-43 uptake, and mechanotransduction currents (data not shown). We suspect that functional redundancy is also in play in utricular hair cells.

How may PAK activity control bundle morphogenesis? We showed that pPAK staining was enriched on the lateral membranes, and in a region adjacent to the base of the bundle and the kinocilium insertion site, where it partially overlapped with mi- crotubules. In explant assays, when PAK activity was inhibited by low-dose IPA-3, we observed flat bundles with off-center kinocilium, whereas higher doses of IPA-3 resulted in fragmentation of the bundle. Based on the staining pattern and the inhibitor experiments, we favor a model where PAK regulates the kinocilium-stereocilia interaction via microtubule-based mechanisms thereby maintaining hair bundle cohesion. Future identification of molecular targets of PAK will reveal the underlying mechanisms by which Rac-PAK signaling regulates hair bundle morphogenesis.

\section{References}

Adler PN (2002) Planar signaling and morphogenesis in Drosophila. Dev Cell 2:525-535.

Belyantseva IA, Boger ET, Naz S, Frolenkov GI, Sellers JR, Ahmed ZM, Griffith AJ, Friedman TB (2005) Myosin-XVa is required for tip localization of whirlin and differential elongation of hair-cell stereocilia. Nat Cell Biol 7:148-156.

Blair A, Tomlinson A, Pham H, Gunsalus KC, Goldberg ML, Laski FA (2006) Twinstar, the Drosophila homolog of cofilin/ADF, is required for planar cell polarity patterning. Development 133:1789-1797.

Bokoch GM (2003) Biology of the p21-activated kinases. Annu Rev Biochem 72:743-781.

Chen L, Liao G, Waclaw RR, Burns KA, Linquist D, Campbell K, Zheng Y, Kuan CY (2007) Racl controls the formation of midline commissures and the competency of tangential migration in ventral telencephalic neurons. J Neurosci 27:3884-3893.

Cho YJ, Zhang B, Kaartinen V, Haataja L, de Curtis I, Groffen J, Heisterkamp N (2005) Generation of rac3 null mutant mice: role of Rac3 in Bcr/Ablcaused lymphoblastic leukemia. Mol Cell Biol 25:5777-5785.

Deacon SW, Beeser A, Fukui JA, Rennefahrt UE, Myers C, Chernoff J, Peterson JR (2008) An isoform-selective, small-molecule inhibitor targets the autoregulatory mechanism of p21-activated kinase. Chem Biol 15:322-331.

El-Amraoui A, Petit C (2005) Usher I syndrome: unravelling the mechanisms that underlie the cohesion of the growing hair bundle in inner ear sensory cells. J Cell Sci 118:4593-4603.

Etheridge SL, Ray S, Li S, Hamblet NS, Lijam N, Tsang M, Greer J, Kardos N, Wang J, Sussman DJ, Chen P, Wynshaw-Boris A (2008) Murine dishevelled 3 functions in redundant pathways with dishevelled 1 and 2 in normal cardiac outflow tract, cochlea, and neural tube development. PLoS Genet 4:e1000259.

Friedman LM, Dror AA, Avraham KB (2007) Mouse models to study inner ear development and hereditary hearing loss. Int J Dev Biol 51:609-631.

Frolenkov GI, Belyantseva IA, Friedman TB, Griffith AJ (2004) Genetic insights into the morphogenesis of inner ear hair cells. Nat Rev Genet 5:489-498.

Glogauer M, Marchal CC, Zhu F, Worku A, Clausen BE, Foerster I, Marks P, Downey GP, Dinauer M, Kwiatkowski DJ (2003) Racl deletion in mouse neutrophils has selective effects on neutrophil functions. J Immunol 170:5652-5657.

Gu Y, Filippi MD, Cancelas JA, Siefring JE, Williams EP, Jasti AC, Harris CE, Lee AW, Prabhakar R, Atkinson SJ, Kwiatkowski DJ, Williams DA (2003) Hematopoietic cell regulation by Rac1 and Rac2 guanosine triphosphatases. Science 302:445-449.

Haataja L, Groffen J, Heisterkamp N (1997) Characterization of RAC3, a novel member of the Rho family. J Biol Chem 272:20384-20388.

Habas R, Dawid IB, He X (2003) Coactivation of Rac and Rho by Wnt/ Frizzled signaling is required for vertebrate gastrulation. Genes Dev 17:295-309.

Hakeda-Suzuki S, Ng J, Tzu J, Dietzl G, Sun Y, Harms M, Nardine T, Luo L, Dickson BJ (2002) Rac function and regulation during Drosophila development. Nature 416:438-442.

Hébert JM, McConnell SK (2000) Targeting of cre to the Foxg1 (BF-1) locus mediates loxP recombination in the telencephalon and other developing head structures. Dev Biol 222:296-306.

Jaffe AB, Hall A (2005) Rho GTPases: biochemistry and biology. Annu Rev Cell Dev Biol 21:247-269.

Jones C, Roper VC, Foucher I, Qian D, Banizs B, Petit C, Yoder BK, Chen P (2008) Ciliary proteins link basal body polarization to planar cell polarity regulation. Nat Genet 40:69-77. 
Lefèvre G, Michel V, Weil D, Lepelletier L, Bizard E, Wolfrum U, Hardelin JP, Petit C (2008) A core cochlear phenotype in USH1 mouse mutants implicates fibrous links of the hair bundle in its cohesion, orientation and differential growth. Development 135:1427-1437.

Leibovici M, Safieddine S, Petit C (2008) Mouse models for human hereditary deafness. Curr Top Dev Biol 84:385-429.

Lelli A, Asai Y, Forge A, Holt JR, Géléoc GS (2009) Tonotopic gradient in the developmental acquisition of sensory transduction in outer hair cells of the mouse cochlea. J Neurophysiol 101:2961-2973.

Lu M, Kinchen JM, Rossman KL, Grimsley C, Hall M, Sondek J, Hengartner MO, Yajnik V, Ravichandran KS (2005) A steric-inhibition model for regulation of nucleotide exchange via the Dock180 family of GEFs. Curr Biol 15:371-377.

Montcouquiol M, Kelley MW (2003) Planar and vertical signals control cellular differentiation and patterning in the mammalian cochlea. J Neurosci 23:9469-9478.

Montcouquiol M, Rachel RA, Lanford PJ, Copeland NG, Jenkins NA, Kelley MW (2003) Identification of Vangl2 and Scrb1 as planar polarity genes in mammals. Nature 423:173-177.

Montcouquiol M, Sans N, Huss D, Kach J, Dickman JD, Forge A, Rachel RA, Copeland NG, Jenkins NA, Bogani D, Murdoch J, Warchol ME, Wenthold RJ, Kelley MW (2006) Asymmetric localization of Vangl2 and Fz3 indicate novel mechanisms for planar cell polarity in mammals. J Neurosci 26:5265-5275.

Muñoz-Descalzo S, Gómez-Cabrero A, Mlodzik M, Paricio N (2007) Analysis of the role of the Rac/Cdc42 GTPases during planar cell polarity generation in Drosophila. Int J Dev Biol 51:379-387.

Ohyama T, Groves AK (2004) Generation of Pax2-Cre mice by modification of a Pax2 bacterial artificial chromosome. Genesis 38:195-199.

Pauley S, Lai E, Fritzsch B (2006) Foxg1 is required for morphogenesis and histogenesis of the mammalian inner ear. Dev Dyn 235:2470-2482.

Petit C, Richardson GP (2009) Linking genes underlying deafness to hairbundle development and function. Nat Neurosci 12:703-710.

Rida PC, Chen P (2009) Line up and listen: planar cell polarity regulation in the mammalian inner ear. Semin Cell Dev Biol 20:978-985.

Ross AJ, May-Simera H, Eichers ER, Kai M, Hill J, Jagger DJ, Leitch CC, Chapple JP, Munro PM, Fisher S, Tan PL, Phillips HM, Leroux MR, Henderson DJ, Murdoch JN, Copp AJ, Eliot MM, Lupski JR, Kemp DT, Dollfus H, et al. (2005) Disruption of Bardet-Biedl syndrome ciliary proteins perturbs planar cell polarity in vertebrates. Nat Genet 37:1135-1140.

Rzadzinska A, Schneider M, Noben-Trauth K, Bartles JR, Kachar B (2005) Balanced levels of Espin are critical for stereociliary growth and length maintenance. Cell Motil Cytoskeleton 62:157-165.

Sekerková G, Zheng L, Mugnaini E, Bartles JR (2006) Differential expression of espin isoforms during epithelial morphogenesis, stereociliogenesis and postnatal maturation in the developing inner ear. Dev Biol 291:83-95.

Self T, Sobe T, Copeland NG, Jenkins NA, Avraham KB, Steel KP (1999) Role of myosin VI in the differentiation of cochlear hair cells. Dev Biol 214:331-341.

Shimada Y, Yonemura S, Ohkura H, Strutt D, Uemura T (2006) Polarized transport of Frizzled along the planar microtubule arrays in Drosophila wing epithelium. Dev Cell 10:209-222.

Stepanyan R, Belyantseva IA, Griffith AJ, Friedman TB, Frolenkov GI (2006) Auditory mechanotransduction in the absence of functional myosinXVa. J Physiol 576:801-808.

Sugihara K, Nakatsuji N, Nakamura K, Nakao K, Hashimoto R, Otani H, Sakagami H, Kondo H, Nozawa S, Aiba A, Katsuki M (1998) Racl is required for the formation of three germ layers during gastrulation. Oncogene 17:3427-3433.

Wang J, Mark S, Zhang X, Qian D, Yoo SJ, Radde-Gallwitz K, Zhang Y, Lin X, Collazo A, Wynshaw-Boris A, Chen P (2005) Regulation of polarized extension and planar cell polarity in the cochlea by the vertebrate PCP pathway. Nat Genet 37:980-985.

Wang J, Hamblet NS, Mark S, Dickinson ME, Brinkman BC, Segil N, Fraser SE, Chen P, Wallingford JB, Wynshaw-Boris A (2006a) Dishevelled genes mediate a conserved mammalian PCP pathway to regulate convergent extension during neurulation. Development 133:1767-1778.

Wang Y, Guo N, Nathans J (2006b) The role of Frizzled3 and Frizzled6 in neural tube closure and in the planar polarity of inner-ear sensory hair cells. J Neurosci 26:2147-2156.

Yan D, Li F, Hall ML, Sage C, Hu WH, Giallourakis C, Upadhyay G, Ouyang XM, Du LL, Bethea JR, Chen ZY, Yajnik V, Liu XZ (2006) An isoform of GTPase regulator DOCK4 localizes to the stereocilia in the inner ear and binds to harmonin (USH1C). J Mol Biol 357:755-764.

Yan J, Lu Q, Fang X, Adler PN (2009) Rhol has multiple functions in Drosophila wing planar polarity. Dev Biol 333:186-199. 